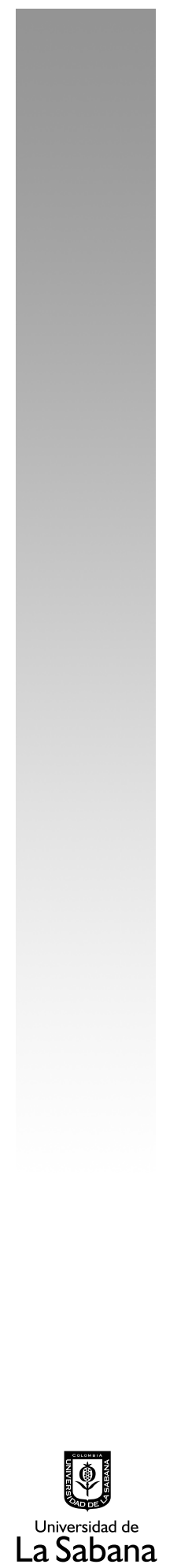

\title{
Fernando Vallespín y Máriam Martínez-Bascuñán, Populismos, Madrid, Alianza Editorial, 2017 , 304 PP.
}

DOI: $10.5294 / D I K A .2019 .28 .1 .8$

\section{NICOLÁS DE NAVASCUÉS*}

Fernando Vallespín, doctor en Ciencia Politica y catedrático de la Universidad Autónoma de Madrid, y Máriam M. Bascuñán, doctora en Ciencia Politica y profesora titular de la misma universidad, se proponen un desmenuzamiento del esqueleto populista de la manera más clara y concienzuda posible. Uno de los logros del libro es la estructura que propone: desde la definición del concepto de populismo y sus causas, hasta llegar a sus objetivos y, finalmente, las formas en que se manifiesta en nuestras democracias, facilita la lectura y la comprensión del hilo argumental. Todo ello para entender de forma precisa este fenómeno, este "espectro (que) recorre las democracias", como reza el primer subtítulo de la Introducción. La postura que adoptan los autores es muy clara, quizás la única válida para un estudio científico de una realidad que opera tanto con la visceralidad y las emociones: "un minimo estudio frío y desapasionado, que es lo que aquí vamos a intentar" (p. 43).

El texto comienza con una Introducción prometedora y desconcertante a partes iguales, en la que empieza repasando la gran aparición de los populismos en nuestras sociedades occidentales en 2016, y el freno que sufren en 2017; continúa con los problemas de nuestro tiempo: "el mundo camina a ciegas, a lomos de 
la incertidumbre y sin saber bien a qué encomendarse" (p. 20), y concluye con la misma idea con la que finaliza todo el libro: todavía queda esperanza, y hay que enfrentarse a los problemas generados por la crisis de la democracia liberal.

Así, sostienen los autores que en Occidente hubo tres grandes momentos populistas: el Brexit, Trump y la segunda vuelta de las elecciones austriacas. En las elecciones holandesas hubo un freno, y llegó lo que los autores llaman "la batalla final, las elecciones presidenciales francesas” (p. 13). La democracia aguantó el embate populista y Macron ganó las elecciones, "el representante de la política sistémica renovada" (p. 14). Estas páginas, que vienen seguidas de una explicación introductoria de cómo en estos últimos años la política tradicional se ha visto amenazada por los movimientos populistas, muestran otro de los puntos por destacar de la obra, a saber: la conjunción entre un análisis académico, expositivo, y las referencias a la realidad política actual, lo empírico, la política que podemos tocar con los dedos en nuestro día a día. El resto de la Introducción explicita algunas de las situaciones de desestabilización o psicosis política, cultural y económica que han ocurrido en la última década en el mundo, y que han servido de caldo de cultivo para el populismo. Con ello se llega a expresar una de las tesis fundamentales de la obra, la contradicción entre la democracia liberal y la economía neoliberal: "se produce así una descompensación entre el principio de legitimidad democrática y los requerimientos de la eficiencia económica” (p. 26).

En estas primeras páginas, además, se expone el hilo del libro, cuestión que facilita la explicación de la secuencia argumental: "el problema es el sustantivo, populismo, [...] es algo que trataremos de abordar en el capítulo 1 del libro” (p. 17), que continúa con el intento de "ofrecer una explicación de por qué reaparece ahora con tanta fuerza, que será objeto del capítulo 2" (p. 18), y un capítulo clave, el tercero, en que se estudia la herramienta de la posverdad y la nueva comunicación desde la democracia digital como sustituto de la democracia mediática. Acerca de los dos últimos capítulos los autores explican que su pretensión es "acercarnos también a un estudio de algunos casos específicos de populismo" (pp. 18-19) y, finalmente, una propuesta del republicanismo como posible cura del problema inserto en nuestras democracias y los problemas relativos a su futuro desarrollo.

Así, en el primer capítulo, titulado “¿Qué es el populismo?”, se hace una búsqueda sistemática y monográfica de las diversas posturas acerca de cómo definir el populismo. Los autores asumen desde el principio la dificultad de la cuestión, porque se trata de "un concepto en disputa" (p. 42). Se ha producido, por un lado, una extensión casi ilimitada de lo que significa el populismo, y, por otro, un uso instrumental por parte de los políticos de lo que significa populista. Recogiendo una brillante intuición de Isaiah Berlin, el populismo sufre el "sindrome de Cenicienta", que vendría a ser algo así como la afirmación de la existencia de un populismo puro -el populismo esencial- pero que no se encuentra, mientras que populismos como derivaciones hay muchos. En el coloquio donde Berlin sostiene esta postura acerca del populismo también se intenta ofrecer una gama de características que servirian para identificar algo como "populismo". Este coloquio, celebrado en 1969, permite a los autores hacer un breve repaso por la historia de este concepto, 
para explicar que los actuales populismos son diferentes, en gran medida por el cambio de la realidad política, y "lo característico de estos nuevos populismos es que nos obligan a incorporar a su definición un rasgo que hoy resulta central, el peculiar estilo o forma de interacción entre el actor político y su público” (p. 50).

Pero lo central de este capítulo consiste en decidir qué método, o qué postura escoger para entender el populismo. Aunque aprecian y admiten la fuerza de la tesis de Mudde, uno de los autores más citados en la obra, acerca de su "enfoque ideacional", y de entender al populismo como "una ideologia delgada, fina (thin), minimalista” (p. 52), los autores optan por tratar de definirlo desde un tipo ideal, desde ese zapato perfecto de Cenicienta, porque esta forma de definición "es quizá la que mejor se ajusta al objeto que nos incumbe" (p. 54).

Esto les permite identificar los diez rasgos del populismo que, a partir de este momento, no dejan de estar presentes en el resto del análisis que llevan a cabo. Quizás los más importantes son la comprensión del populismo como una "lógica de acción política" y no como una ideologia política propiamente, y la creación de un antagonista, la polarización de la sociedad en el binomio schmittiano amigo-enemigo. Así, explican que el populismo no consiste en una ideología, ni micro ni macro -siguiendo la distinción de teorías micro/macro de Freeden-, "porque su concepto central, pueblo y la correlativa idea de soberanía popular, está muy lejos de ser claro y permite todo tipo de aleaciones o promiscuidades ideológicas” (p. 59).

El resto del capítulo se ocupa de explicar el pensamiento de Laclau, y logra hacerlo de forma realmente brillante y sencilla, incluso teniendo en cuenta que, como los propios autores reconocen, "a pesar de lo farragoso de sus textos no hay más remedio que considerar como el único teórico, junto con su compañera Chantal Mouffe, que proporciona una elaborada presentación propia de qué es el populismo y cuál debería ser su estrategia” (p. 61). Se desarrollan así las tesis del autor argentino en torno a lo antagónico, la creación del dualismo maniqueo, la construcción del "pueblo" y, sobre todo, de esa brillante intuición de Laclau que recorre como premisa o primer principio toda su estrategia. Se trata de los "significantes tendencialmente vacios", que permiten, por su indefinición, "ser ocupados con una multiplicidad de contenidos" (p. 65).

Una vez los autores han logrado encontrar su tipo ideal, pasan en el segundo capítulo a pensar en sus causas, que dividen en varios apartados. El lector agradece esta división, tanto por el rigor multidisciplinar, como por la simplificación que ofrece a la hora de la segmentación del contenido. Vemos, por tanto, en “¿Por qué el populismo?”, tres partes: los factores socioeconómicos, los factores culturales y psicosociales, y el factor propiamente politico. No podemos olvidar, por un lado, que el gran brote populista llega después de la crisis de 2008, con "las formidables sacudidas que está introduciendo la globalización” (p. 92). La enorme división entre 180 rentas bajas y rentas altas, que en los movimientos sociales se vio representada con el "We are the 99\%", es representada gráficamente por Vallespín y Bascuñán con el conocido grafico del "cuello del elefante" de Milanovic (p. 101). 
En cuanto a los factores psicosociales, quizás la parte más débil del análisis causal -olvida el psicoanálisis lacaniano, presente en el populismo-, los autores identifican fundamentalmente las grandes divisiones generacionales como ruptura en las preferencias politicas. Así, citan a Norris cuando sostiene que la "ruptura entre jóvenes y viejos votantes parece haber reemplazado a la de clase social” (p. 114), todo ello por la división entre los nuevos valores progresistas y los viejos valores del proletariado. Finalmente, se plantea la cuestión política, con una de las tesis más fuertes que se subrayan a lo largo de toda la obra: si puede haber democracia, que no sea liberal. Esa es la pretensión del populismo, primar a Rousseau sobre Locke y destruir las instancias mediadoras, las instituciones, para convertir al lider en representante puro del pueblo. En unas iluminadoras páginas, los autores advierten que la palabra "crisis", como la palabra "populista", se está convirtiendo en algo vacío, que sirve para acusar al político de turno. Pero "algo que siempre está en crisis en realidad nunca lo está” (p. 120).

No es casualidad que, en la llave del libro, el capitulo 3, se encuentren algunas de las nuevas herramientas, instrumentos que propician la existencia del populismo. Están fundadas en una nueva realidad tecnológica, por lo que esta parte de la obra es un eje perfecto: se encuentra entre las causas -y es que el uso de lo tecnológico es causa de ascenso- y las formas de populismo o las consecuencias de los populismos existentes -que una vez existen, que la causa ha dado lugar a la aparición de un populismo, utilizan las herramientas digitales-.

Tanto es así que se hace una distinción aquí entre "el tipo ideal de democracia mediática" y "su supuesto sucesor, la democracia digital" (p. 146), aquella aprovechada por los populismos. Por otro lado, este capítulo se diferencia de los demás por su mayor originalidad, y, sobre todo, por ser más especulativo que los siguientes, y mucho más que los anteriores. En una muestra de cómo se intenta ofrecer una explicación holística y multidisciplinar de los populismos, se atraviesa desde la explicación de los nuevos medios de comunicación a la posición de preeminencia que otorga el populismo a los sentimientos sobre la razón, y se menciona incluso la neurociencia, como vemos en el apartado "Emociones desatadas".

Ahora es posible ver las diferentes formas en que el populismo se manifiesta. Ese es el objeto del cuarto capítulo, "Variedades de populismos", que estudia en extensión tres casos: el populismo norteamericano, el francés y el español. En cuanto a Estados Unidos, se comienza por el Tea Party, ese movimiento que tiene "una agenda neoliberal en lo económico y un rechazo feroz contra el Estado de bienestar", y con una serie de "posiciones anti: antigobierno, antiimpuestos, antiinmigración” (p. 195). A continuación, se habla brevemente del populismo progresista Occupy Wall Street para, finalmente, tratar el inesperado surgimiento de la Alt Right y el triunfo de Trump.

En el caso de Francia se centra en el Frente Nacional, y aquí vemos que los autores sienten un respeto o admiración por Marine Le Pen que no sienten por Trump; en dos ocasiones la llaman "animal político", y su epígrafe se titula "Marine Le Pen: un verdadero animal político". Se sigue la misma estructura que para Estados 
Unidos: una descripción de los fundamentos políticos de estos movimientos. Es el caso español, Podemos, el que rompe esta estructura: se presupone el conocimiento de la programática del partido morado y se permiten hacer un análisis más profundo, con la ventaja de que sus propios dirigentes son intelectuales populistas. Resulta, así, muy interesante leer la reflexión acerca de cómo Iglesias y Errejón hacen su interpretación, por ejemplo, de la hegemonía, como dirigentes políticos de Podemos y buenos conocedores de la obra de Laclau y Mouffe. Todo ello, claro, "a partir de los escritos de Gramsci” (p. 241).

Finalmente tenemos el capítulo más breve, "Populismo y democracia". La primera parte está dedicada a una fina y complicada reflexión acerca de la noción de democracia y la propuesta republicana para resolver el problema surgido en la teoría de la democracia, al que ya se apuntaba en la Introducción con el caso chino, acerca del que decían los autores que "con el tiempo creará una quiebra importante en el imaginario de la democracia, a saber: la denegación empírica de la conexión entre prosperidad económica [...] y democracia” (p. 30). En la segunda parte, al hablar del "para qué" del populismo, se vuelve a cuestiones más empíricas y se plantea que "la mejor forma de describir lo que significa el populismo [es] [...] en la descripción de qué es lo que hacen una vez que acceden al poder" (p. 272). Esta es la razón de un último repaso dado a los populismos que han llegado al poder para concluir con una última llamada a la esperanza: frente al Gran Rechazo de los populismos, que proponen un "así no", los autores dicen que "es posible que aún estemos a tiempo de eludir la Gran Regresión”, que aparezca una política realmente positiva, para darnos "una gran Progresión” (p. 279).

El tratamiento latinoamericano es uno de los aspectos del trabajo que no termina de convencer. A pesar de la advertencia que hacen los autores en el comienzo, "por estas peculiaridades del populismo latinoamericano, este no será objeto de una atención especial en este libro" (nota a pie 22, capítulo 1), las referencias a este se suceden a lo largo de las páginas. Es comprensible no tratar de abarcar un tema tan amplio como el populismo latinoamericano en una obra centrada en los populismos actuales occidentales, pero también se entiende la imposibilidad de hablar de populismo y omitir América Latina. Cómo no pensar en los descamisados de Evita Perón al escuchar en nuestros días las nuevas construcciones de pueblo, sean cuales sean.

En conclusión, podemos afirmar que se trata de una obra imprescindible para comprender el virus que amenaza nuestras democracias occidentales tal y como las conocemos. Con una extensa bibliografia, que el académico agradece a la hora de leer acerca de un tema tan visceral y sentimental, y un muy buen uso de los aspectos de la política empírica para no caer en meros argumentos abstractos, se trata de una obra sumamente medida, casi monográfica en ocasiones, pero multidisciplinar para entender "el cómo algo tan sencillo pueda ser envuelto en una compleja teoría filosófica” (nota a pie 5, capítulo 5). 